\title{
EDUCAÇÃO ALIMENTAR E NUTRICIONAL E A FORMAÇÃO DE HÁBITOS ALIMENTARES NA INFÂNCIA
}

\author{
Cláudia Thomé da Rosa Piasetzki ${ }^{1}$ \\ Eva Teresinha de Oliveira Boff ${ }^{2}$
}

\begin{abstract}
RESUMO
A conformação dos hábitos alimentares e de características do estilo de vida se iniciam na infância, são consolidadas na adolescência e, frequentemente, mantidas na idade adulta. Apresentamos um mapeamento de produções científicas cujo objetivo foi identificar e analisar o que e como vem sendo investigado sobre a temática educação alimentar e nutricional e formação de hábitos alimentares na infância. Foram analisadas as produções científicas disponíveis nos periódicos do portal da Capes e nas bases de dados Scielo, publicadas no período de 2007 a 2017 com a utilização dos descritores "Educação Alimentar e Nutricional + Criança". Compuseram o corpus da pesquisa 29 artigos, dos quais emergiram quatro categorias de análise. A compreensão das categorias foi apoiada no referencial histórico cultural, com base em Vigotsky (2007, 2008). Os artigos analisados mostram que existem estudos sobre Educação Alimentar e Nutricional na Infância, mas, na maioria das vezes, não passam de atividades pontuais, geralmente sem continuidade.
\end{abstract}

Palavras-chave: Educação alimentar e nutricional. Criança. Formação de hábitos alimentares.

\section{FOOD AND NUTRITIONAL EDUCATION AND THE FORMATION OF EATING HABITS IN CHILDHOOD}

\section{ABSTRACT}

The conformation of eating habits and lifestyle characteristics begins in childhood, it is consolidated in adolescence and often maintained in adulthood. We present a mapping of scientific productions whose objective was to identify and analyze what and how it has been investigated on the theme of food and nutrition education and the formation of eating habits in childhood. We analyzed the scientific production, available in Capes portal journals and Scielo databases, published between 2007 and 2017, using the descriptors "Food and Nutrition Education + Child". The research corpus was composed by 29 articles, from which four categories of analysis emerged. The understanding of the categories was supported by the cultural historical reference, based on Vigotsky (2007 and 2008). The analyzed papers show that there are studies on Food and Nutrition Education in Childhood, but most of the time they are only occasional activities, usually without continuity.

Keywords: Food and nutritional education. Child. Formation of eating habits.

RECEBIDO EM: 12/5/2018

ACEITO EM: 2/7/2018

\footnotetext{
${ }^{1}$ Nutricionista na Secretaria de Saúde e Educação do município de Bozano/RS. Doutoranda no Programa de Pós-Graduação em Educação em Ciências: Química da Vida e Saúde (UFRGS). Mestre em Educação nas Ciências - Unijuí. claudiapiasetzki@hotmail.com

2 Professora doutora em Educação em Ciências vinculada ao Departamento de Ciências da Vida da Universidade Regional do Noroeste do Estado do Rio Grande do Sul - Unijuí. Atua no PPG Educação em Ciências/Mestrado e Doutorado/Unijuí e no Educação em Ciências: Química da Vida e Saúde/UFRGS. evaboff@unijui.edu.br.
} 
Neste texto apresentamos um mapeamento de produções científicas, com o objetivo de analisar o que vem sendo investigado sobre a educação alimentar e nutricional e a formação de hábitos alimentares na infância, sendo este um tema investigado tanto no campo da saúde quanto no da educação (BRASIL, 2008a, 2014; BRASIL 1997, 1998, 2013).

A Educação Alimentar e Nutricional (EAN) abrange desde os aspectos relacionados ao alimento e à alimentação até os processos de produção, abastecimento e transformação dos alimentos em relação aos aspectos nutricionais (BRASIL, 2012a).

A EAN é um campo de ação da Segurança Alimentar e Nutricional e da Promoção da Saúde e tem sido considerada uma estratégia fundamental para a prevenção e controle dos problemas alimentares e nutricionais contemporâneos. Entre seus resultados potenciais identifica-se a contribuição na prevenção e controle das doenças crônicas não transmissíveis e deficiências nutricionais, bem como a valorização das diferentes expressões da cultura alimentar, o fortalecimento de hábitos regionais, a redução do desperdício de alimentos, a promoção do consumo sustentável e da alimentação saudável (BRASIL, 2012a, p. 13).

Para compreender melhor os termos Alimentar e Nutricional, começamos pelo significado da palavra Alimentação:

A alimentação é um ato voluntário e consciente. Ela depende totalmente da vontade do indivíduo e é o homem quem escolhe o alimento para o seu consumo. A alimentação está relacionada com as práticas alimentares, que envolvem opções e decisões quanto à quantidade; o tipo de alimento que comemos; quais os que consideramos comestíveis ou aceitáveis para nosso padrão de consumo; a forma como adquirimos, conservamos e preparamos os alimentos; além dos horários, do local e com quem realizamos nossas refeições (BRASIL, 2007, p. 16).

A alimentação não ocorre apenas para suprir as necessidades biológicas; ela está internalizada na cultura do indivíduo e depende de sua vontade e disponibilidade. Segundo a Política Nacional de Alimentação e Nutrição, a alimentação é um elemento de humanização das práticas de saúde. Ela expressa as relações sociais, valores e história do indivíduo e dos grupos populacionais, além de ter implicações diretas na saúde e na qualidade de vida (BRASIL, 2012a). Já o significado da palavra Nutrição está acima da vontade do sujeito:

A nutrição é um ato involuntário, uma etapa sobre a qual o indivíduo não tem controle. Começa quando o alimento é levado à boca. A partir desse momento, o sistema digestório entra em ação, ou seja, a boca, o estômago, o intestino e outros órgãos desse sistema começam a trabalhar em processos que vão desde a trituração dos alimentos até a absorção dos nutrientes, que são os componentes dos alimentos que consumimos e são muito importantes para a nossa saúde (BRASIL, 2007, p. 16).

A Nutrição é o estado fisiológico resultante do consumo alimentar e da utilização biológica de energia e nutrientes em nível celular (BRASIL, 2013). Ou seja, ela independe da vontade do indivíduo e é um processo autônomo do corpo, mas é consequência da alimentação. 
Desse modo, de acordo com o Marco de Referência de Educação Alimentar e Nutricional para as Políticas Públicas:

Educação Alimentar e Nutricional, no contexto da realização do Direito Humano à Alimentação Adequada e da garantia da Segurança Alimentar e Nutricional, é um campo de conhecimento e de prática contínua e permanente, transdisciplinar, intersetorial e multiprofissional que visa promover a prática autônoma e voluntária de hábitos alimentares saudáveis. A prática da EAN deve fazer uso de abordagens e recursos educacionais problematizadores e ativos que favoreçam o diálogo junto a indivíduos e grupos populacionais, considerando todas as fases do curso da vida, etapas do sistema alimentar e as interações e significados que compõem o comportamento alimentar (BRASIL, 2012a, p. 23).

A EAN faz parte de um conjunto de estratégias criadas para promover a alimentação adequada e saudável.

Alimentação adequada e saudável: prática alimentar apropriada aos aspectos biológicos e socioculturais dos indivíduos, bem como ao uso sustentável do meio ambiente. Deve estar de acordo com as necessidades de cada fase do curso da vida e com as necessidades alimentares especiais; ser referenciada pela cultura alimentar e pelas dimensões de gênero, raça e etnia; ser acessível do ponto de vista físico e financeiro; harmônica em quantidade e qualidade; baseada em práticas produtivas adequadas e sustentáveis; com quantidades mínimas de contaminantes físicos, químicos e biológicos (BRASIL, 2012c, p. 67).

Estas questões relativas à saúde começaram a ganhar mais espaço no contexto escolar a partir de 1971 com a Lei 5.692, no artigo 70, que estabeleceu a obrigatoriedade de inclusão de Programas de Saúde nos currículos de 1ㅇ e 2ㅇ Graus. Gradativamente a abordagem do tema saúde se aprofundou, culminando na perspectiva transversal por meio dos Parâmetros Curriculares Nacionais-PCNs (BRASIL, 1998) e, no momento atual, mediante a Base Nacional Comum Curricular (BRASIL, 2017). Sob essa abordagem, o currículo aporta as principais questões de saúde, cuja concepção considera determinantes sociais bem como as dimensões individuais e coletivas (BRASIL, 2012b).

Torna-se importante o desenvolvimento e a compreensão de estratégias que promovam a conformação dos hábitos alimentares e características do estilo de vida saudáveis como algo constitutivo do currículo escolar. Nesta linha de pensamento, Vigotsky (2007, p. 87) afirma que:

Os problemas encontrados na análise psicológica do ensino não podem ser corretamente resolvidos ou mesmo formulados sem nos referirmos à relação entre o aprendizado e o desenvolvimento em crianças em idade escolar. Este ainda é o mais obscuro de todos os problemas básicos necessários à aplicação de teorias de desenvolvimento da criança aos processos educacionais. É desnecessário dizer que essa falta de clareza teórica não significa que o assunto esteja completamente à margem dos esforços correntes de pesquisa em aprendizado; nenhum dos estudos pode evitar essa questão teórica central.

Defendemos que a internalização de conceitos e a conscientização a respeito de uma alimentação e estilo de vida saudáveis, podem proporcionar mudanças de hábitos alimentares com maior efetividade quando iniciadas na infância e na juventude. Estudar 
e discutir as questões da alimentação e estilo de vida com estudantes de Educação Básica pode contribuir para a construção de aprendizagens inerentes ao currículo escolar numa abordagem integral do sujeito.

Para compreender como se dá a formação de conceitos em relação à configuração de hábitos alimentares saudáveis na infância, nos apoiamos no referencial histórico cultural de Vigotsky $(2007,2008)$. O autor mostra em suas pesquisas que a criança desenvolve suas faculdades mentais superiores na interação com o outro e que o processo de formação de conceitos se inicia na infância e desenvolve-se até a adolescência, sempre em interação com outros.

Considerando a necessidade de identificar e analisar o que vem sendo divulgado sobre o tema, realizamos um mapeamento dos artigos científicos publicados no Portal de Periódicos da Capes e nas bases de dados Scielo no período de 2007 a 2017. A questão central norteadora do processo de pesquisa é: $O$ que se mostra sobre a educação alimentar e nutricional e a formação de hábitos alimentares na infância, nas produções científicas disponíveis nos periódicos do portal da Capes e nas bases de dados Scielo, publicadas no período de 2007 a 2017? Temos como hipótese que houve avanços nas produções científicas em relação a esta temática, mas, pelo que se observa na realidade escolar, ainda são insuficientes para compreender como se dá a formação de hábitos alimentares saudáveis de modo articulado com o currículo escolar.

\section{OS PRESSUPOSTOS TEÓRICO-METODOLÓGICOS}

A pesquisa é qualitativa do tipo revisão sistemática e se constitui na primeira etapa de realização de tese de Doutorado. Fizemos um mapeamento das produções científicas disponíveis nos periódicos do portal da Capes e nas bases de dados Scielo no período de janeiro de 2007 a dezembro de 2017. Utilizamos para a busca os descritores "Educação Alimentar e Nutricional + Criança".

No Portal de Periódicos da Capes, com o termo "Educação Alimentar e Nutricional", encontramos 1.699 resultados. Como estes foram da população em geral, optamos por refinar a busca com a inclusão do termo "Criança", obtendo, para estes descritores, 473 resultados. Ao delimitar o período, de 2007 a 2017, obtivemos 242 resultados. Destes, 223 foram artigos científicos, 5 livros, 12 recursos textuais e 1 tese. Selecionamos apenas os artigos revisados por pares, obtendo um total de 180 artigos científicos, os quais foram lidos e analisados na íntegra. Destes, mesmo abordando o tema criança, a maioria não focalizava o assunto educação alimentar e nutricional, restando apenas 25 artigos ligados diretamente ao tema proposto para o estudo.

Quanto à busca na base de dados Scielo com o termo "Educação Alimentar e Nutricional", encontramos 294 resultados, e refinando a pesquisa, com a adição da palavra "criança", encontramos 38 resultados. Destes 38 artigos, 21 eram os mesmos já encontrados no Portal de Periódicos da Capes. Desse modo, restaram 17 artigos para serem lidos e analisados na íntegra, dos quais apenas 4 apresentaram ligação direta com o tema de estudo. Ao total compuseram o corpus da pesquisa, 29 artigos científicos. 
Para análise do corpus utilizamos a Análise Textual Discursiva (ATD) de Moraes e Galiazzi (2016), os quais orientam para um processo de desconstrução, unitarização e categorização. A ATD "corresponde a uma metodologia de análise de informações de natureza qualitativa com a finalidade de produzir novas compreensões sobre os fenômenos e discursos" (p. 13).

A ATD "não pretende testar hipóteses para comprová-las ou refutá-las ao final da pesquisa; a intenção é a compreensão, a reconstrução de conhecimentos existentes sobre os temas investigados" (p. 33). Examinamos a ATD organizando os argumentos em quatro focos, conforme proposto pelos autores. Os três primeiros focos compõem um ciclo, no qual se constituem como elementos principais a Desmontagem dos Textos, o Estabelecimento de Relações e a Captação do Novo Emergente. O quarto foco surge a partir do transcorrer do ciclo como Um Processo Auto-Organizado.

O primeiro foco do ciclo de análise - a Desmontagem dos Textos -, também chamada de desconstrução e unitarização, consiste, inicialmente, em estabelecer uma relação entre a leitura dos textos e sua interpretação, para possibilitar a construção de significados a partir do conjunto de textos estudados (MORAES; GALIAZZI, 2016). Neste sentido, a ATD caracteriza-se como uma análise fenomenologia pela descrição dos fenômenos, e também como hermenêutica, pela necessidade de interpretação dos mesmos.

O segundo foco - Estabelecimento de Relações - consiste no confronto das unidades retiradas do corpus e a emergência da categorização de análise. "As categorias são constituintes da compreensão que emerge do processo analítico" (MORAES; GALIAZZI, 2016, p. 44).

Ao definir as categorias e expressá-las "descritivamente a partir dos elementos que as constituem, inicia-se um processo de explicitação de relações entre elas no sentido da construção da estrutura de um metatexto" (MORAES; GALIAZZI, 2016, p. 51). A construção do metatexto compõe o terceiro foco, denominado Captação do novo emergente.

O quarto foco da ATD consiste em um processo auto-organizado e complexo resultante do ciclo como um todo. Deste processo, emergem as compreensões.

Entendemos a ATD como uma metodologia de caráter fenomenológico e hermenêutico, em que se valoriza o sujeito em seus modos de expressão dos fenômenos e se interpreta aquilo que se estuda por meio da hermenêutica.

\section{O PROCESSO DE DESCRIÇÃO E INTERPRETAÇÃO DAS PRODUÇÕES CIENTÍFICAS}

Apresentamos neste item os resultados obtidos da análise dos 29 artigos que compuseram o corpus da pesquisa, posto que somente estes tiveram relação direta com o tema de estudo. A partir da análise do corpus da pesquisa emergiram quatro categorias: a) a influência da família para a formação dos hábitos alimentares na infância; b) educação alimentar e nutricional: uma possibilidade de trabalho em equipe entre escola, professor e nutricionista; c) a influência dos meios de comunicação e as empresas de alimentos nas escolhas alimentares; d) EAN na Infância para a continuidade dos padrões alimentares à adolescência e à vida adulta (Quadro I). 


\section{Quadro 1 - Síntese dos trabalhos encontrados nos periódicos representados por categorias de análise}

\begin{tabular}{|c|c|c|c|c|c|c|c|}
\hline \multirow[t]{2}{*}{$\mathbf{N}$} & \multirow[t]{2}{*}{ Artigo } & \multirow[t]{2}{*}{ Autor } & \multirow[t]{2}{*}{$\begin{array}{l}\text { Periódicos/Período } \\
(2007 / 2017)\end{array}$} & \multicolumn{4}{|c|}{ Categorias de análise } \\
\hline & & & & a) & b) & c) & d) \\
\hline 1 & $\begin{array}{c}\text { Avaliação do material didático } \\
\text { do projeto "Criança Saudável - } \\
\text { Educação Dez". }\end{array}$ & OLIVEIRA, K. S. & $\begin{array}{l}\text { Interface - } \\
\text { Comunicação, } \\
\text { Saúde, Educação, } \\
2008 .\end{array}$ & V & & & \\
\hline 2 & $\begin{array}{l}\text { A importância da educação } \\
\text { nutricional na infância para } \\
\text { prevenção da obesidade. }\end{array}$ & $\begin{array}{l}\text { RESENDE, V. A.; NAVARRO, } \\
\text { A. C. }\end{array}$ & RBONE, 2008. & & & & $\sqrt{ }$ \\
\hline 3 & $\begin{array}{l}\text { Determinantes do comportamento } \\
\text { alimentar: uma revisão com } \\
\text { enfoque na família. }\end{array}$ & $\begin{array}{l}\text { ROSSI, A.; MOREIRA, E. A. } \\
\text { M.; RAUEN, M. S. }\end{array}$ & $\begin{array}{c}\text { Revista de } \\
\text { Nutrição, } 2008 .\end{array}$ & V & $\mathrm{V}$ & & \\
\hline 4 & $\begin{array}{c}\text { A alimentação orgânica e as ações } \\
\text { educativas na escola: diagnóstico } \\
\text { para a educação em saúde e } \\
\text { nutrição. }\end{array}$ & $\begin{array}{l}\text { CUNHA, E.; SOUSA, A. A.; } \\
\text { MACHADO, N. M. V. }\end{array}$ & $\begin{array}{l}\text { Revista Ciência \& } \\
\text { Saúde Coletiva, } \\
2010 .\end{array}$ & & $\mathrm{V}$ & & \\
\hline 5 & $\begin{array}{c}\text { Projeto "Criança Saudável, } \\
\text { Educação Dez": Resultados com e } \\
\text { sem intervenção do nutricionista". }\end{array}$ & $\begin{array}{l}\text { DETREGIACHI, C. R. P.; } \\
\text { BRAGA, T. M. S. }\end{array}$ & $\begin{array}{c}\text { Revista de } \\
\text { Nutrição, } 2011 .\end{array}$ & & $v$ & & \\
\hline 6 & $\begin{array}{l}\text { A pesquisa sobre alimentação no } \\
\text { Brasil: sustentando a autonomia do } \\
\text { campo alimentação e nutrição. }\end{array}$ & $\begin{array}{l}\text { PRADO, S. D.; BOSI, M. L. } \\
\text { M.; CARVALHO, M. C. V. S.; } \\
\text { GUGELMIN, S. A.; KLOTZ- } \\
\text { SILVA, J.; DELMASCHIO, K. L. }\end{array}$ & $\begin{array}{l}\text { Revista Ciência \& } \\
\text { Saúde Coletiva, } \\
2011 .\end{array}$ & & 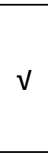 & & \\
\hline 7 & $\begin{array}{l}\text { Preferência alimentar de crianças } \\
\text { e adolescentes: revelando a } \\
\text { ausência de conhecimento sobre a } \\
\text { alimentação saudável. }\end{array}$ & $\begin{array}{l}\text { CAMBRAIA, R. P.; MURTA, } \\
\text { N. M. G.; CAMPOS, M. H. } \\
\text { O.; BOTELHO, L. A. }\end{array}$ & $\begin{array}{c}\text { Revista } \\
\text { Alimentação e } \\
\text { Nutrição, } 2012 .\end{array}$ & & & & v \\
\hline 8 & $\begin{array}{c}\text { Diabetes mellitus tipo 1: vivência } \\
\text { dos pais em relação à alimentação } \\
\text { de seu filho. }\end{array}$ & $\begin{array}{l}\text { CORRÊA, A.; FRANCO, S.; } \\
\text { DEMÁRIO, R. L.; SANTOS, } \\
\text { F. S. }\end{array}$ & $\begin{array}{c}\text { Revista } \\
\text { Alimentação e } \\
\text { Nutrição, } 2012 . \\
\end{array}$ & 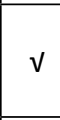 & & & \\
\hline 9 & $\begin{array}{l}\text { Child feeding practices and house } \\
\text { hold food in security amonglow - } \\
\text { income mothers in Buenos. }\end{array}$ & $\begin{array}{l}\text { LINDSAY, A. C.; FERARRO, } \\
\text { M.; FRANCHELLO, A.; LA } \\
\text { BARRERA, L.; MACHADO, } \\
\text { M. M. T.; PFEIFFER, M. E.; } \\
\text { PETERSON, K. E. }\end{array}$ & $\begin{array}{l}\text { Revista Ciência \& } \\
\text { Saúde Coletiva, } \\
2012 .\end{array}$ & V & & & \\
\hline 10 & $\begin{array}{l}\text { Manutenção dos padrões } \\
\text { alimentares da infância à } \\
\text { adolescência. } \\
\end{array}$ & $\begin{array}{l}\text { MADRUGA, S. W.; ARAÚJO, } \\
\text { C. L. P.; BERTOLDI, A. D.; } \\
\text { NEUTZLING, M. B. } \\
\end{array}$ & $\begin{array}{l}\text { Revista Saúde } \\
\text { Pública, } 2012 .\end{array}$ & & & & V \\
\hline 11 & $\begin{array}{c}\text { Validação de metodologias ativas } \\
\text { de ensino-aprendizagem na } \\
\text { promoção da saúde alimentar } \\
\text { infantil. }\end{array}$ & $\begin{array}{l}\text { MAIA, E. R.; LIMA JUNIOR, } \\
\text { J. F.; PEREIRA, J. S.; ELOI, A. } \\
\text { C.; GOMES, C. C.; NOBRE, } \\
\text { M. M. F. }\end{array}$ & $\begin{array}{c}\text { Revista de } \\
\text { Nutrição, } 2012 .\end{array}$ & & $\mathrm{V}$ & & \\
\hline 12 & $\begin{array}{l}\text { Hábitos alimentares de pré- } \\
\text { escolares: a influência das mães e } \\
\text { da amamentação. }\end{array}$ & $\begin{array}{l}\text { OLIVEIRA, A. S.; SILVA, V. A. } \\
\text { P.; ALVES, J. J.; FAGUNDES, } \\
\text { D.; PIRES, I. S. C.; MIRANDA, } \\
\text { L. S. }\end{array}$ & $\begin{array}{c}\text { Revista } \\
\text { Alimentação e } \\
\text { Nutrição, } 2012 .\end{array}$ & 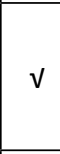 & & & \\
\hline 13 & $\begin{array}{c}\text { Era uma vez ... um olhar sobre } \\
\text { o uso dos contos de fada como } \\
\text { ferramenta de educação alimentar } \\
\text { e nutricional. }\end{array}$ & JUZWIAK, C. R. & $\begin{array}{l}\text { Revista Interface: } \\
\text { Comunicação } \\
\text { Saúde Educação, } \\
2013 . \\
\end{array}$ & $v$ & $v$ & & \\
\hline 14 & $\begin{array}{l}\text { Percepções de educadores } \\
\text { de creches acerca de práticas } \\
\text { cotidianas na alimentação } \\
\text { de lactentes: impacto de um } \\
\text { treinamento. }\end{array}$ & $\begin{array}{l}\text { LONGO-SILVA, G.; TADDEI, J. } \\
\text { A. A. C.; KONSTANTYNER, T.; } \\
\text { TOLONI, M. H. A. }\end{array}$ & $\begin{array}{l}\text { Revista Ciência \& } \\
\text { Saúde Coletiva, } \\
2013 .\end{array}$ & & $v$ & & \\
\hline 15 & $\begin{array}{l}\text { Aconselhamento nutricional de } \\
\text { crianças menores de dois anos. }\end{array}$ & $\begin{array}{l}\text { CAMPOS, A. A. O.; COTA, R. } \\
\text { M. M.; OLIVEIRA, J. M. O.; } \\
\text { SANTOS, A. K.; ARAÚJO, R. } \\
\text { M. A. }\end{array}$ & $\begin{array}{l}\text { Ciência \& Saúde } \\
\text { Coletiva, } 2014 .\end{array}$ & & $\mathrm{V}$ & & \\
\hline
\end{tabular}




\begin{tabular}{|c|c|c|c|c|c|c|c|}
\hline 16 & $\begin{array}{l}\text { Perfis parentais com base nas } \\
\text { práticas educativas e alimentares: } \\
\text { análises por agrupamento. }\end{array}$ & $\begin{array}{l}\text { MAYER, A. P. F.; WEBER, L. } \\
\text { N. D.; TON, C. T. }\end{array}$ & $\begin{array}{c}\text { Revista Psicologia, } \\
\text { Saúde \& Doenças, } \\
2014 . \\
\end{array}$ & $v$ & & & \\
\hline 17 & \begin{tabular}{|c|} 
Caracterização do desenvolvimento \\
da alimentação em crianças de 6 a \\
24 meses.
\end{tabular} & $\begin{array}{l}\text { SCHAURICH, G. F.; } \\
\text { DELGADO, S. E. }\end{array}$ & $\begin{array}{l}\text { Revista Cefac, } \\
2014 .\end{array}$ & & & & $v$ \\
\hline 18 & $\begin{array}{c}\text { Publicidade de alimentos e escolhas } \\
\text { alimentares de crianças. }\end{array}$ & $\begin{array}{l}\text { UEDA, M. H.; PORTO, R. B.; } \\
\text { VASCONCELOS, L. A. }\end{array}$ & $\begin{array}{l}\text { Revista Psicologia: } \\
\text { Teoria e Pesquisa, } \\
2014 \\
\end{array}$ & & & $v$ & \\
\hline 19 & $\begin{array}{l}\text { Alimentação saudável e } \\
\text { dificuldades para torná-la uma } \\
\text { realidade: percepções de pais/ } \\
\text { responsáveis por pré-escolares de } \\
\text { uma creche em Belo Horizonte/ } \\
\text { MG, Brasil. }\end{array}$ & $\begin{array}{c}\text { BENTO, I. C.; ESTEVES, J. M. } \\
\text { M.; FRANÇA, T. E. }\end{array}$ & $\begin{array}{l}\text { Revista Ciência \& } \\
\text { Saúde Coletiva, } \\
2015 .\end{array}$ & $v$ & & & \\
\hline 20 & $\begin{array}{c}\text { Capacitação de crianças com } \\
\text { dificuldades intelectuais para boas } \\
\text { práticas alimentares. } \\
\end{array}$ & $\begin{array}{l}\text { BONÉ, M. A.; BONITO, J.; } \\
\text { CALDEIRA, V. }\end{array}$ & $\begin{array}{l}\text { Revista Holos, } \\
2015 .\end{array}$ & & $v$ & & \\
\hline 21 & $\begin{array}{c}\text { Fatores associados ao consumo } \\
\text { de bebidas açucaradas entre pré- } \\
\text { escolares brasileiros: inquérito } \\
\text { nacional de } 2006 \text {. }\end{array}$ & $\begin{array}{l}\text { VEGA, J. B.; POBLACION, A. } \\
\text { P.; TADDEI, J. A. A. C. }\end{array}$ & $\begin{array}{l}\text { Ciência \& Saúde } \\
\text { Coletiva, } 2015 .\end{array}$ & & & $\mathrm{V}$ & \\
\hline 22 & $\begin{array}{c}\text { Educational software and } \\
\text { improvement of first grade school } \\
\text { students' knowledge about } \\
\text { prevention of overweight and } \\
\text { obesity. }\end{array}$ & $\begin{array}{l}\text { COELHO, L. S. V. A.; NOVAIS, } \\
\text { F. R. V. N.; MACEDO, G. A.; } \\
\text { SANTOS, J. N. N.; SOUSA; V. } \\
\text { L.; MENDES, L. A. M. }\end{array}$ & $\begin{array}{l}\text { Invest. Educ. } \\
\text { Enferm, } 2016 .\end{array}$ & & $v$ & & \\
\hline 23 & $\begin{array}{c}\text { Representations by Caregivers, } \\
\text { Teachers, and Children on Food, } \\
\text { Nutrition, Health, and School } \\
\text { Breakfast. }\end{array}$ & $\begin{array}{l}\text { GALLEGOS-MARTÍNEZ J.; } \\
\text { REYES-HERNÁNDEZ, J. }\end{array}$ & $\begin{array}{l}\text { Revista Invest. } \\
\text { Educ. Enferm., } \\
\quad 2016\end{array}$ & $v$ & & & \\
\hline 24 & $\begin{array}{c}\text { Comportamento alimentar no } \\
\text { campo da alimentação e nutrição: } \\
\text { Do que estamos falando? }\end{array}$ & $\begin{array}{l}\text { KLOTZ-SILVA, J.; PRADO, S. } \\
\text { D.; SEIXAS, C. M. }\end{array}$ & $\begin{array}{l}\text { Physis Revista de } \\
\text { Saúde Coletiva, } \\
2016 .\end{array}$ & & & & v \\
\hline 25 & \begin{tabular}{|c|} 
Situação da alimentação \\
complementar de crianças entre 6 \\
e 24 meses assistidas na Rede de \\
Atenção Básica de Saúde de Macaé, \\
RJ, Brasil. \\
\end{tabular} & $\begin{array}{l}\text { MARINHO, L. M. F.; } \\
\text { CAPELLI, J. C. S.; ROCHA, } \\
\text { C. M. M.; BOUSKELA, A.; } \\
\text { CARMO, C. N.; PEREIRA DE } \\
\text { FREITAS, S. E. A. }\end{array}$ & $\begin{array}{l}\text { Ciência \& Saúde } \\
\text { Coletiva, } 2016 .\end{array}$ & & & & v \\
\hline 26 & $\begin{array}{l}\text { Association between maternal life } \\
\text { style and preschool nutrition. }\end{array}$ & $\begin{array}{l}\text { NOBRE, É. B.; BRENTANI, A. } \\
\text { V. M.; FERRARO, A. A. }\end{array}$ & $\begin{array}{c}\text { Revista da } \\
\text { Associação Médica } \\
\text { Brasileira, 2016. } \\
\end{array}$ & $v$ & & & \\
\hline 27 & $\begin{array}{l}\text { Adesão a recomendações } \\
\text { alimentares em pré-escolares: } \\
\text { ensaio clínico com mães } \\
\text { adolescentes. }\end{array}$ & $\begin{array}{l}\text { SOLDATELI, B.; VIGO, A.; } \\
\text { GIUGLIANI, E. R. J. }\end{array}$ & $\begin{array}{l}\text { Revista de Saúde } \\
\text { Pública, } 2016 .\end{array}$ & $v$ & & & \\
\hline 28 & $\begin{array}{l}\text { A interdisciplinaridade como } \\
\text { estratégia na prevenção da } \\
\text { hipertensão arterial sistêmica em } \\
\text { crianças: uma revisão sistemática. }\end{array}$ & BERNARDI, L. & $\begin{array}{l}\text { Revista Ciência \& } \\
\text { Saúde Coletiva, } \\
2017\end{array}$ & & $\sqrt{ }$ & & \\
\hline 29 & $\begin{array}{c}\text { Food marketing targeting children: } \\
\text { unveiling the ethical perspectives in } \\
\text { the discourse on self-regulation. }\end{array}$ & $\begin{array}{l}\text { SILVA, D. A. C.; CUNHA, } \\
\text { A. C. R.; CUNHA, T. R.; } \\
\text { ROSANELI, C. F. } \\
\end{array}$ & $\begin{array}{c}\text { Revista Ciência \& } \\
\text { Saúde Coletiva, } \\
2017 . \\
\end{array}$ & & & $\mathrm{V}$ & \\
\hline & Total de Artigos & - & - & 11 & 11 & 3 & 6 \\
\hline
\end{tabular}

Podemos observar, no Quadro 1, que os trabalhos encontrados nos periódicos representaram, em sua maioria, as categorias de análise referentes à influência da família para a formação dos hábitos alimentares na infância e a educação alimentar e nutricional: uma possibilidade de trabalho em equipe entre escola, professor e nutricionista, sendo estas categorias encontradas em 11 periódicos cada. 
Já as categorias influência dos meios de comunicação e as empresas de alimentos nas escolhas alimentares e a EAN na infância para a continuidade dos padrões alimentares à adolescência e à vida adulta, foram encontradas em três e seis periódicos respectivamente.

A seguir apresentamos detalhadamente a descrição das quatro categorias de análise emergentes do corpus da pesquisa:

\section{Categoria a:}

\section{A influência da família para a formação dos hábitos alimentares na infância}

\section{Análise descritiva dos artigos}

Juzwiak (2013) escreveu sobre as histórias infantis como instrumento de EAN para pré e escolares. Destaca que "inicialmente, a família representa o principal fator de influência sobre o padrão alimentar das crianças" (p. 473). Os pais são os responsáveis pela oferta de alimentos das crianças, portanto suas escolhas influenciam, significativamente, no desenvolvimento dos hábitos alimentares.

Ao nascer e entrar em contato com o novo mundo que a cerca, a criança está exposta a estímulos de toda natureza. É também nesse momento que entrará em contato com os alimentos e iniciará o processo de estabelecimento de hábitos alimentares que podem perdurar por toda a vida (JUZWIAK, 2013, p. 473).

Durante a infância, ao mesmo tempo em que a alimentação é importante para o crescimento e desenvolvimento, ela também pode representar um dos principais fatores para a prevenção de algumas doenças que possam se desenvolver na fase adulta (ROSSI; MOREIRA; RAUEN, 2008). Nesta fase da vida a família exerce grande influência sobre o padrão alimentar das crianças.

Oliveira (2008) afirmou que "o padrão alimentar dos pais é um aspecto importantíssimo a ser considerado, pois são eles que criam condições em casa, para a prática de uma alimentação saudável ou não" (p. 404).

Corrêa et al. (2012) realizaram um estudo com o objetivo de conhecer a experiência dos pais de crianças e adolescentes diabéticos em relação à alimentação de seus filhos. Os resultados revelaram uma mudança na dinâmica familiar após o diagnóstico da doença, e a maior dificuldade encontrada foi a mudança nos hábitos alimentares de toda a família. "O comportamento alimentar de crianças e adolescentes é, invariavelmente, reflexo dos hábitos alimentares da família" (p. 634).

Nesta linha de pensamento, Oliveira et al. (2012) fizeram um estudo com o objetivo de avaliar a influência da alimentação das mães, as características da amamentação e a introdução de novos alimentos nos hábitos alimentares de 134 crianças de 4 a 6 anos de idade.

O fato da maioria das crianças passarem maior parte do tempo sob os cuidados da própria mãe pode aumentar a influência da mesma sobre os hábitos alimentares de seus filhos, que pode ser tanto positiva quanto negativa, dependendo da cultura e conhecimentos de cada mãe (OLIVEIRA et al., 2012, p. 383). 
A associação do estilo de vida materno com a nutrição de pré-escolares foi investigada por Nobre, Brentani e Ferraro (2016), acreditando que muitos comportamentos de saúde envolvidos no surgimento de doenças crônicas não transmissíveis são originados na infância com a influência dos pais ou familiares. Segundo os autores, a mãe é a pessoa mais envolvida na educação dos filhos, assim como nos cuidados de saúde das crianças, sendo seu estilo de vida um determinante social de saúde. Os autores descobriram que crianças com alimentação minimamente processada eram filhas de mães com estilos de vida socioconsciente, e crianças com alimentação ultraprocessada eram filhas de mães com estilos de vida consumista. Não foi encontrada associação entre as características nutricionais do pré-escolar e os estilos de vida materna, porém os autores conseguiram concluir que as mães com estilos de vida consumista podem proporcionar influências negativas para a nutrição infantil (NOBRE; BRENTANI; FERRARO, 2016).

Bento, Esteves e França (2015) realizaram um estudo para conhecer as percepções de pais ou responsáveis por pré-escolares matriculados em uma creche, buscando compreender o que eles entendiam por alimentação saudável e quais as suas dificuldades para se alimentarem de maneira adequada. Observaram que os responsáveis pelas crianças tinham uma noção do que é uma alimentação saudável, porém seus discursos evidenciaram práticas alimentares inadequadas. As principais dificuldades apontadas para obter uma alimentação saudável foram os recursos financeiros, falta de tempo e hábito alimentar.

Os responsáveis pelas crianças precisam ser estimulados e sensibilizados a melhorar a sua alimentação, pois suas práticas alimentares influenciam as de seus filhos. Os autores também salientaram a necessidade de estratégias de educação alimentar e nutricional que possibilitem aos responsáveis reconhecer e ter uma alimentação saudável (BENTO; ESTEVES; FRANÇA, 2015).

Do mesmo modo, Gallegos-Martínez e Reyes-Hernández (2016) apoiaram uma intervenção educativa fundamentada na família como figura central para outorgar nas crianças uma boa alimentação e ensinar bons hábitos alimentares.

Já Soldateli, Vigo e Giugliani (2016), em seus estudos, demonstraram que intervenções educativas para mães e avós nos primeiros quatro meses de vida das crianças não têm efeito positivo ao cumprimento de recomendações alimentares para essas crianças dos quatro a sete anos de vida. Confirmaram também a má qualidade da alimentação de crianças pré-escolares e a necessidade de intervenções efetivas.

Mayer, Weber e Ton (2014), por sua vez, analisaram a relação entre os estilos parentais, as práticas alimentares e o desenvolvimento nutricional dos filhos. Os dados analisados mostraram a importância da família para o desenvolvimento nutricional das crianças.

As análises por perfis das práticas educativas alimentares maternas e paternas identificaram diversas variáveis que podem estar afetando a interação familiar, o repertório educativo dos pais e mães e o desenvolvimento das crianças. Entre elas, a situação conjugal, o trabalho materno, o gênero dos filhos, o número de irmãos, o IMC parental, o desempenho acadêmico da criança, a escolaridade paterna e o nível econômico da família (MAYER; WEBER; TON, 2014, p. 694). 
As autoras constataram a necessidade de investigar, em pesquisas futuras, outras variáveis, "como a idade e geração dos pais, a relação entre as práticas observadas e a percepção dos filhos, e maior diversidade de práticas educativas globais, como a comunicação, a punição, o controle psicológico e a intrusividade" (MAYER; WEBER; TON, 2014, p. 694).

Os autores ressaltaram a necessidade de preparar pais e mães para a educação alimentar dos seus filhos, assim como alertá-los de que práticas de restrição alimentar ou o uso da alimentação como forma de controle podem trazer prejuízos ao desenvolvimento das crianças (MAYER; WEBER; TON, 2014).

Um estudo realizado com mães de baixa renda de Buenos Aires, na Argentina, examinou a influência de condições socioeconômicas, estrutura organizacional, relações familiares e insegurança alimentar sobre as práticas de alimentação e padrão de peso infantil. Muitas mães apresentaram-se cientes de que a obesidade pode ser prejudicial para a saúde das crianças, mas a maioria não tem clareza a respeito das consequências. As práticas de alimentação infantil parecem ser influenciadas, segundo o estudo, pelo trabalho materno, pelas pressões familiares, pela insegurança alimentar e pelas preocupações financeiras (LINDSAY, 2012).

\section{Interpretação na base do referencial de Vigotsky}

A análise das produções descritas mostra que a família desempenha um importante papel na formação dos hábitos alimentares, pois são os pais ou responsáveis que compram e preparam os alimentos que serão oferecidos às crianças. As preferências alimentares dos filhos são influenciadas pelas escolhas e hábitos alimentares de seus pais.

De acordo com Vigotsky (2008), uma das leis fundamentais que regem o desenvolvimento psicológico afirma que "a consciência e o controle aparecem apenas num estágio tardio do desenvolvimento de uma função, após esta ter sido utilizada e praticada inconscientemente e espontaneamente" (p. 103). Desse modo, entendemos que uma criança não é responsável psicologicamente por suas escolhas alimentares em razão de estas serem influenciadas pelo meio em que estão inseridas, porém, no decorrer das repetições das práticas alimentares cotidianas, estas vão se tornando hábitos, mesmo ainda inconscientes.

É importante ter uma alimentação saudável em todas as fases da vida, independente do estado de saúde. Neste aspecto, não há o termo privação alimentar e sim adequação. Acreditamos que quando se desenvolvem hábitos alimentares saudáveis desde cedo em uma criança, ela os levará consigo no decorrer de sua vida. Embora esses hábitos ainda estejam sujeitos a modificações, dependendo do meio em que esta criança estiver inserida, o desenvolvimento de hábitos alimentares saudáveis na infância implica desenvolvimento da consciência e de "um conjunto de capacidades independentes ou um conjunto de hábitos específicos" (VIGOTSKY, 2008, p. 93).

Afirmamos, em virtude dos estudos apresentados, que a família, independente de quem sejam seus integrantes - pais, irmãos, avós, tios ou cuidadores -, tem profunda influência sobre a formação dos hábitos alimentares das crianças. Por mais que esses hábitos possam sofrer modificações, muito da cultura alimentar "herdada" da sua 
família é levada como conceito para a vida, sejam hábitos saudáveis ou não. A escola, no entanto, também pode exercer forte influência na formação de hábitos alimentares saudáveis se a EAN estiver na centralidade da ação pedagógica no cotidiano escolar.

\section{Categoria b:}

Educação alimentar e nutricional: uma possibilidade de trabalho em equipe entre escola, professor e nutricionista

\section{Análise descritiva dos artigos}

Além da família, "outros fatores, como a escola, a rede social, as condições socioeconômicas e culturais, são potencialmente modificáveis e influenciam no processo de construção dos hábitos alimentares da criança" (ROSSI; MOREIRA; RAUEN, 2008, p. 740).

Vestena, Scremin e Bastos (2018, p. 368) destacam que a escola se constitui em espaço de convivência que "desempenha um papel-chave de aprendizagem e mudança de comportamento quanto à alimentação, seja por meio da merenda escolar, seja pelas práticas pedagógicas desenvolvidas com os alunos que tenham relação com a temática". A escola, então, é a primeira instituição formal responsável pela formação das crianças quanto aos conteúdos das áreas do conhecimento. A escola é "o ponto de partida para novos conhecimentos, portanto, deve considerar a percepção prévia dos estudantes sobre o mundo natural e social em que estão imersos e isso inclui os hábitos para uma alimentação saudável" (VESTENA; SCREMIN; BASTOS, 2018, p. 370).

Campos et al. (2014) analisaram os estudos sobre as práticas do aconselhamento em alimentação de crianças menores de dois anos de idade, discutindo as potencialidades e os obstáculos encontrados para o estabelecimento de práticas de alimentação saudável. As ações educativas de aconselhamento em alimentação infantil foram direcionadas aos profissionais de saúde e aos cuidadores das crianças menores de dois anos de idade. Destacaram, como potencialidades da prática do aconselhamento nutricional, "melhora no desempenho dos profissionais de saúde, adoção de práticas alimentares saudáveis pelos cuidadores e melhora no estado nutricional das crianças" (p. 529). Ressaltaram como obstáculos a "falta de capacitação dos cuidadores e profissionais quanto à alimentação complementar saudável e dificuldade quanto à prática do aconselhamento por profissionais de saúde" (p. 529). As autoras reafirmaram a importância de incorporar ações de aconselhamento em alimentação infantil às políticas de atenção à saúde da criança, como práticas permanentes.

Longo-Silva et al. (2013) avaliaram o impacto de um treinamento de educadoras de creches nas percepções e nas práticas acerca da alimentação infantil. Perceberam que as educadoras apresentam dificuldades em lidar com a rejeição das crianças a certos tipos de alimentos e com a demanda de tempo necessária para a introdução de alimentos.

As educadoras pensam que, da mesma forma que a nutricionista passa as orientações para a cozinha, devia passar para elas, para que possam entender as mudanças e porque não pode tal alimento, até em relação às quantidades que se coloca no prato 
que é oferecido para à criança. Muitas vezes as professoras acabam por trazer bolachas, salgadinhos e pipocas de casa e oferecem escondido para as crianças quando estas não gostam da comida (LONGO-SILVA et al., 2013).

Após a realização de um treinamento com duração de 40 horas sobre nutrição e saúde de lactentes, Longo-Silva et al. (2013) observaram indícios de pequenas mudanças ou o reconhecimento de que é preciso e é possível mudar.

Afonso (2008) analisou o currículo formal do 10 Ciclo do Ensino Básico de Portugal e concluiu que os conceitos definidos no programa nacional, relativos à alimentação e nutrição, são escassos, pouco claros e pouco objetivos. O autor sugere que seria importante que os cursos de formação inicial de professores contemplassem a educação para a saúde no seu currículo, com temas específicos de alimentação e nutrição. Ainda, deveriam existir também orientações técnicas, que guiassem a intervenção do professor no sentido da promoção da saúde e, especificamente, da educação nutricional. Do mesmo modo, Detregiachi e Braga (2011) destacam a importância da atenção dada ao componente educação na formação dos profissionais nutricionistas.

Com o ingresso da criança na escola, o processo de estabelecimento de hábitos alimentares passa a sofrer maior influência do meio; "a criança realiza refeições fora de casa (alimentação escolar, compra na cantina), o alimento passa a ter outra representação social importante (amigos), e o ambiente escolar torna-se a principal fonte de conhecimento formal sobre nutrição" (JUZWIAK, 2013, p. 473).

A partir de um alimento, é possível criar uma rede de conteúdos a serem trabaIhados nas disciplinas tradicionais e em atividades extras, permitindo que as questões alimentares e nutricionais sejam desenvolvidas transversalmente, incluindo a participação de todos os atores envolvidos no processo - estudantes, professores, comunidade escolar e família. Os contos de fada tradicionais abrem inúmeras possibilidades (JUZWIAK, 2013, p. 478).

O tema hortaliças, por exemplo, nos remete à horta como uma poderosa ferramenta de educação nutricional, permitindo a consolidação da educação integral. A autora supra destaca que a construção de hortas escolares, no coletivo, possibilita "promover a educação integral de crianças e jovens de escolas e comunidades do seu entorno [...] incorporando a alimentação nutritiva, saudável e ambientalmente sustentável como eixo gerador da prática pedagógica" (BRASIL, 2008b, p. 7).

No cuidado à criança, a alimentação é de fundamental importância para a promoção da saúde, pois o significado do ato de nutrir ultrapassa o mero ato biológico (MAIA et al., 2012).

Em um estudo de Coelho et al. (2016), os autores avaliaram os efeitos da utilização de um software educativo na melhora dos conhecimentos de escolares sobre o tema prevenção de sobrepeso e obesidade. Ao comparar os momentos antes e depois da utilização do software, os autores observaram diferenças estatisticamente significativas na proporção das perguntas respondidas corretamente pelos escolares, principalmente no que se refere à ingestão diária de alimentos saudáveis e não saudáveis, preparação adequada dos alimentos e a importância da realização de atividade física. 
Professores referiram ter dificuldades em sistematizar conteúdos sobre alimentação que ultrapassem o conteúdo proposto pelo livro didático. Existe uma carência de informações teóricas para possibilitar que os professores trabalhem esse tema (CUNHA; SOUSA; MACHADO, 2010).

Prado et al. (2011, p. 107), com base em estudos de Bourdieu relacionados aos campos científicos, realizaram uma abordagem crítica de pesquisas brasileiras com foco na alimentação e identificaram:

Um conjunto estável e crescente de grupos de pesquisa, cuja visibilidade fica comprometida uma vez que sua denominação não consta das taxonomias institucionais no âmbito das agências de fomento à pesquisa e à formação de pesquisadores. Seus fundamentos epistemológicos, suas bases teórico-metodológicas, situam-se na esfera das humanidades e incluem uma ampla gama de disciplinas em interação, conformando significativa complexidade em torno de seu objeto central: a "comida". O estudo dos fenômenos alimentares reclama a interdisciplinaridade e apresenta como desafio o enfrentamento das tensões inerentes à vida democrática na qual vislumbramos um devir em que a convivência crescente e colaborativa entre diferentes referências epistêmicas deve ter lugar institucional.

Outro desafio é apresentado por Boné, Bonito e Caldeira (2015), ao mostrarem um trabalho de capacitação de crianças com dificuldades intelectuais para boas práticas alimentares, enfatizando a importância da introdução de sequências didáticas que visem à capacitação, nas escolas, de crianças com dificuldades intelectuais para práticas alimentares saudáveis.

Pesquisas que desenvolvam ações interdisciplinares em escolas são defendidas por Bernardi et al. (2017) como significativas na modificação de níveis de pressão arterial e consumo de sódio por crianças, quando as intervenções combinam educação nutricional com atividade física, sendo realizadas por um longo período de tempo.

R. P. N. Silva et al. (2017) relatam a falta de materiais didáticos como a principal dificuldade dos professores para trabalhar na escola o tema saúde. Do mesmo modo, os docentes apresentam uma concepção sobre saúde insuficiente para o ensino, pois o tema abordado normalmente está atrelado ao modelo biomédico/patológico, em detrimento da concepção de educar para a saúde. Também a maioria dos cursos de formação continuada para os professores com a temática saúde são "voltados à orientação e à prevenção de doenças" (SILVA, R. P. N. et al., 2017, p. 161).

Os autores destacam que é importante trabalhar o tema saúde na escola, porém não se deve falar de educação em saúde apenas para prevenir ou orientar doenças. Também é responsabilidade do professor e da escola "proporcionar ao aluno a apropriação de conhecimentos significativos, capacitando-os para tomadas de decisão individuais, de modo a favorecer a compreensão da aplicabilidade de seus atos e decisões na sociedade em que vive e no mundo" (SILVA, R. P. N. et al., 2017, p. 161).

\section{Interpretação na base do referencial de Vigotsky}

Acreditamos que todos os trabalhos relacionados à educação alimentar e nutricional funcionariam melhor se houvesse uma ação interdisciplinar. No caso das creches, por exemplo, seria interessante se o nutricionista trabalhasse em conjunto com professores e merendeiras, realizando formações com estes profissionais sobre alimentação 
saudável e introdução de alimentos, para que estes possam realmente compreender o porquê dos alimentos contidos nos cardápios e porque não devem oferecer outros alimentos industrializados e artificiais, além da merenda da escolar. Para todos os fatores descritos aqui, entendemos que o trabalho em equipe é o melhor método para a Educação Alimentar e Nutricional das crianças, pois os professores precisam compreender o processo que se passa diariamente com suas crianças.

De acordo com Vigotsky (2008, p. 27),

A criança pensa de forma sincrética sobre assuntos de que não tem conhecimento ou experiência, mas não recorre ao sincretismo com relação às coisas familiares ou que sejam de fácil comprovação prática - e o número dessas coisas depende do método de educação.

Estes estudos nos chamam atenção para a importância de atividades educativas em ambiente escolar que despertem com maior intensidade o interesse e curiosidade da criança. As atividades, porém, não devem ser somente pontuais, mas estarem inseridas no contexto escolar, fazendo parte do Projeto Pedagógico da escola, para que realmente seja possível formar conceitos escolares articulados a hábitos alimentares e estilos de vida saudáveis.

Marques e Carvalho (2017, p. 7), embasados no referencial histórico-cultural de Vigotsky, entendem que:

Não há entre o homem e o mundo uma relação direta. Sua visão de mundo, sua percepção, suas escolhas, enfim, sua atividade no mundo e com o mundo passa pela mediação das significações. Isso quer dizer que o modo como professores e alunos significam suas relações, significam o que fazem e o que vivenciam, determinam sua subjetividade e, consequentemente, sua atividade. Nesse processo de mediação, os afetos movimentam os sujeitos porque orientam a produção de sentidos e, por conseguinte, o modo como se relacionam com a realidade.

A reflexão do professor com os estudantes sobre seus hábitos alimentares e estilo de vida, pode contribuir de alguma forma para a prevenção de futuros problemas de saúde. O diagnóstico precoce de alguns hábitos inadequados pode contribuir para a conscientização sobre a importância da alimentação e estilo de vida saudável, promover mudanças e produzir sentidos e significados aos conteúdos escolares.

Desse modo, destacamos a escola como importante espaço e momento para a realização de ações de EAN. Por meio da interação entre professores e nutricionista é possível articular este tema ao currículo escolar, promovendo saúde e um maior entendimento dos conteúdos escolares relacionados com a temática.

Categoria c:

A influência dos meios de comunicação e as empresas de alimentos sobre as escolhas alimentares

\section{Análise descritiva dos artigos}

O público infantil é um dos mais visados para a publicidade de alimentos. D. A. C. Silva et al. (2017) realizaram uma pesquisa com o objetivo de "conhecer o discurso contrário à regulação, por parte do Estado, da publicidade de alimentos direcionada a 
crianças e adolescentes" (p. 2.189). De acordo com os autores, "a característica ética da publicidade brasileira é um discurso trazido pronto, calculado, fechado, intocado, naturalizado e não aberto a diálogo" (SILVA, D. A. C. et al., 2017, p. 2.190).

A ética da publicidade não pode ser considerada uma ética de proteção aos vulneráveis, pois não assume responsabilidade sobre suas escolhas. Defende o acesso à informação, porém essa informação não é sobre os danos que a exposição à publicidade pode causar às crianças e adolescentes (SILVA, D. A. C. et al., 2017, p. 2.190). A publicidade, na maioria das vezes, contraria princípios

bioéticos como o da proteção aos vulneráveis, a publicidade é uma influência indevida sobre as possíveis decisões ou escolhas alimentares de crianças e adolescentes, e prejudica-Ihes a autonomia. Sabe-se, também, que a liberdade para realizar escolhas alimentares é influenciada por fatores outros além da informação disponível; é determinada pelo poder de compra e é influenciada pelas tradições culturais, preferências, hábitos, e até mesmo pelas mensagens publicitárias (SILVA, D. A. C. et al., 2017, p. 2.191).

Ueda, Porto e Vasconcelos (2014) analisaram o efeito de vídeos de desenhos com publicidade de alimentos saudáveis e não saudáveis em contraposição a vídeos neutros sobre as escolhas alimentares. Os resultados mostraram que, com a mudança de vídeo, as crianças variaram em até $13 \%$ a escolha de alimentos saudáveis ou não após a publicidade, havendo, portanto, efeito dos vídeos saudáveis e não saudáveis, conduzindo as escolhas de alimentos saudáveis e não saudáveis, respectivamente. Assim, o aumento da exibição de publicidade de alimentos saudáveis e a diminuição da publicidade de alimentos não saudáveis pode contribuir para a alimentação saudável.

Vega, Poblacion e Taddei (2015) observaram que as crianças que vivem em regiões com maior desenvolvimento econômico pertencem a famílias de maior poder aquisitivo e que suas mães têm o hábito de assistir televisão e, sistematicamente, têm mais chance de serem consumidores frequentes de bebidas açucaradas.

\section{Interpretação na base do referencial de Vigotsky}

Atualmente a televisão, internet e demais meios de comunicação ocupam lugares de destaque nas relações familiares. Algumas empresas de alimentos se aproveitam disso para iludir os consumidores, fazendo com que eles acreditem ser necessário consumir seus produtos. A propaganda veiculada pela mídia tem grande impacto na vida das crianças, transmitindo representações destorcidas da infância. Os produtos industrializados representam a modernidade e atendem ao gosto popular, mesmo sendo, muitas vezes, prejudiciais à saúde.

Uma criança não nasce com uma cultura própria formada; ela é moldada pela sociedade em que vive. Do mesmo modo, uma criança não nasce gostando de açúcar, gorduras e produtos industrializados; ela adquire estes gostos por meio dos estímulos e hábitos contínuos de consumo.

De acordo com Vigotsky (2008), "o verdadeiro curso do desenvolvimento do pensamento não vai do individual para o socializado, mas do social para o individual" ( $p$. 24). Enfatizamos, portanto, a importância de o ambiente em que a criança está inserida 
ser de hábitos alimentares e estilos de vida saudáveis. Considerando a noção de mediação de Vigotsky (2008), o conceito se refere à maneira como o meio social, em que a criança está inserida, cria ou converte as relações sociais em funções mentais.

\section{Categoria d:}

EAN na infância para a continuidade dos padrões alimentares à adolescência e à vida adulta

\section{Análise descritiva dos artigos}

Madruga et al. (2012) realizaram um estudo sobre padrões alimentares da infância e verificaram que estes podem persistir até a adolescência, embora possam ser alterados ou descontinuados "substancialmente durante o crescimento, mas o registro e a importância do primeiro aprendizado e algumas formas sociais aprendidas permanecem ao longo do ciclo vital" (p. 385).

Marinho et al. (2016) fizeram uma pesquisa com o objetivo de analisar a situação da alimentação complementar de crianças entre 6 e 24 meses. Eles observaram que houve aumento do consumo de alimentos saudáveis e também de alimentos não saudáveis com o avanço da idade em ambos os sexos. O suco industrializado foi o alimento que se destacou dentre os outros marcadores de alimentação não saudável.

Schaurich e Delgado (2014) também caracterizaram a alimentação de crianças entre 6 e 24 meses realizando entrevista com os responsáveis. "Verificaram que refrigerantes e salgadinhos eram consumidos por $80,7 \%$ e $76,1 \%$ das crianças. Dos responsáveis, $47,7 \%$ receberam informações sobre introdução dos alimentos do pediatra" ( $p$. 1.579). Nesta pesquisa, novamente vemos o consumo de alimentos considerados não saudáveis por crianças em desenvolvimento de hábitos alimentares.

$\mathrm{Na}$ infância a criança aprende os alimentos que ela gosta e os alimentos que ela não gosta. Esse aprendizado acontece por meio da repetida ingestão de alimentos associada aos sabores, à satisfação fisiológica e ao ambiente social em que a criança está inserida (RESENDE; NAVARRO, 2008).

A "educação nutricional contribui para a difusão da alimentação saudável, sendo que um dos passos iniciais em uma intervenção é o conhecimento do valor subjetivo atribuído aos alimentos ou preparações" (CAMBRAIA et al., 2012, p. 483). A Educação Nutricional tem fundamental importância para a promoção de hábitos alimentares e, como consequência, a prevenção da obesidade e doenças relacionadas a ela (CAMBRAIA et al., 2012).

Klotz-Silva, Prado e Seixas (2016) afirmam que os comportamentos e os hábitos alimentares "são termos utilizados no campo da Alimentação e Nutrição, em que se destaca a ideia de autores que percebem os comportamentos como eventos controláveis e cuja repetição altera o hábito" (p. 1.103).

Na perspectiva do pensamento complexo, o comportamento se desloca de ação condicionada para uma extensão que comporta as dimensões sociocultural, subjetiva e individual, consciente e inconsciente, enquanto o hábito se afirma como 
aquilo que na repetição faz sentido para o indivíduo, permitindo que este possa apropriar-se de forma singular das informações e orientações provenientes da ciência e sustentar suas mudanças (KLOTZ-SILVA; PRADO; SEIXAS, 2016, p. 1.103).

Os autores pretendem, em seus estudos, entender os comportamentos alimentares, buscando referências no campo das Ciências Humanas e Sociais, tentando encontrar um caminho para o controle dos desejos e impulsos. Assim afirmam que:

No campo da Alimentação e Nutrição, trata-se, portanto, de abordar o comportamento em sua relação com o hábito, não de forma simplificadora, mas considerando a complexidade da vida e do ser humano. A obstinação pela prevenção e pela cura que se apoia no uso ingênuo desses termos expõe com seu fracasso que o comportamento não pode ser controlado, o ser humano e seus hábitos não podem ser condicionados (p. 118).

\section{Interpretação na base do referencial de Vigotsky}

Vigotsky (2008), por meio da psicologia histórico-cultural, destaca o caráter social da psicogênese do desenvolvimento humano. Segundo ele, é a cultura que constitui o próprio lócus do desenvolvimento, sendo este uma função da interação do homem com o meio/grupo social em que está inserido e não como uma função individual que seja programada biologicamente. Assim, o homem não nasce com sua cultura pronta; ela é moldada por meio do convívio em sociedade que definirá os conceitos a serem formados durante o processo de transformação intelectual.

Para Vigotsky (2008), o processo de formação de conceitos normalmente se inicia na infância e desenvolve-se até a adolescência, quando atinge a maturidade. 0 processo de formação de conceitos passa por três fases básicas, cada uma sendo dividida em vários estágios. Do ponto de vista lógico, são considerados três estágios no processo de formação de conceitos: pensamento sincrético, pensamento por complexos e pensamento conceitual.

O pensamento sincrético, também chamado de agregação desorganizada, ou amontoado, manifesta-se quando a criança pequena começa a agrupar alguns objetos para resolver um problema, que, nos adultos, teoricamente com "nossa mente formada", resolveríamos com a formação de um novo conceito. Este primeiro estágio, que representa para a criança o significado de uma determinada palavra artificial, baseia-se em tentativa e erro no desenvolvimento do pensamento. Assim, podemos imaginar que é também nesta fase que a criança iniciará a formação de um conceito de alimentação. Este poderá ser relacionado a uma alimentação rica em produtos naturais, frutas, verduras, enfim uma alimentação balanceada e saudável, ou associar o conceito de alimentação a produtos industrializados, como refrigerantes, salgadinhos, balas, biscoitos, ou qualquer outro tipo de "alimento" comprado no supermercado.

A segunda fase, considerada por Vigotsky (2008) como a mais importante no processo para a formação de conceitos, é chamada de pensamento por complexos. Neste, as associações corretas começam a se formar na mente da criança, sendo uma passagem para um nível muito mais elevado, característico de que a criança já superou seu egocentrismo. "O pensamento por complexos já constitui um pensamento coerente e objetivo, embora não reflita as relações objetivas do mesmo modo que o pensamento 
conceitual" (p. 76). Neste segundo momento, a formação de conceitos, que ocorre na adolescência, já foi iniciada, mas, como os conceitos ainda não estão completos, há a oportunidade de produzir novos significados por meio do uso da palavra em diferentes contextos. Assim, se um adolescente iniciou sua formação de conceitos quando ainda criança, associando alimentação a alimentos industrializados, sem se dar conta de que estes são ricos em calorias, sem demais valores nutritivos, com elevados teores de aditivos químicos ou conservantes, ainda conseguimos interagir com ele sobre os perigos que estes podem causar para a saúde e dialogar sobre o significado de uma alimentação que seja o mais saudável possível.

A terceira fase ocorre após o pensamento por complexos completar todo o seu curso de desenvolvimento; é como se o pensamento por complexo fosse uma raiz da formação de conceitos e este terceiro constituísse uma segunda raiz, independente (VIGOTSKY, 2008). Possui uma função genética especifica no que diz respeito ao desenvolvimento mental da criança, diferente daquela dos complexos (VIGOTSKY, 2008). Para formar esse conceito é preciso abstrair, isolar elementos e examiná-los em detalhes, separadamente da totalidade do concreto em que se encontram (VIGOTSKY, 2008).

$\mathrm{Na}$ adolescência, período em que a formação de conceitos se estabelece, embora não seja concluída, pode se observar que as formas primitivas de pensamento (sincréticas e por complexos) desaparecem gradualmente (VIGOTSKY, 2008). Os conceitos potenciais vão sendo cada vez menos usados e começam a se formar os verdadeiros conceitos (VIGOTSKY, 2008). Lembramos que qualquer palavra usada pela criança, mesmo na mais tenra infância, é conceito potencial; a criança a usa sem a consciência do significado, mas esta palavra pode evoluir para, mais tarde, formar os verdadeiros conceitos.

Quando os verdadeiros conceitos estão formados, e se entre eles está a alimentação e esta não está sendo adequada ao indivíduo, há uma maior dificuldade na adoção ou até mesmo modificação de hábitos alimentares e de estilos de vida mais saudáveis. Assim, acreditamos que uma criança que iniciou sua formação de conceitos aprendendo sobre uma alimentação e estilos de vida saudáveis, terá maior facilidade para desenvolvê-los durante a adolescência e formar os verdadeiros conceitos, seguindo e mantendo o pensamento saudável para a sua vida adulta. Ainda quanto a este aspecto, a escola e a família, apresentam-se como espaço de mediação para este processo de ensino e aprendizagem.

De acordo com Marques e Carvalho (2017), embasados pela psicologia histórico-cultural de Vigotsky, "Os significados e os sentidos medeiam ainda a transformação de determinadas experiências de vida dos sujeitos em vivências à medida que levam à produção de sentidos que alteram a forma do homem relacionar-se com a realidade" (p. 5), sendo a vivência uma "categoria da psicologia sócio-histórica fundamental para o entendimento do processo de constituição humana" (MARQUES; CARVALHO, 2017, p. 5).

A relação do homem com o mundo e com os outros é sempre uma relação afetiva produtora de sentido. Os sentidos são produzidos em virtude dos afetos constituídos nas vivências de cada ser humano. Entendemos com isso que são os afetos que colocam os indivíduos em situação de atividade ou de passividade, porque são os afetos que determinam a qualidade do sentido produzido pelo indivíduo na relação com a realidade. Queremos dizer que enquanto para uns uma vivência pode ser 
sentida de forma positiva, para outros a mesma situação pode ser vivida de forma negativa. Isso acontece porque cada pessoa produz um sentido para aquilo que vive, cada pessoa sente de forma única e constrói sua relação com dado fenômeno de forma única, mas sempre mediado pelo social e pelo significado historicamente constituído (MARQUES; CARVALHO, 2017, p. 7).

Considerando a importância dos diferentes estágios de formação de conceitos, conforme o pensamento de Vigotsky (2008), sincrético, complexo e conceitual, e as reflexões a respeito destes, entendemos que o processo de Educação Alimentar e Nutricional, com a constituição de hábitos alimentares e estilo de vida saudáveis, tem maior efetividade se iniciado no período da infância, tanto na família quanto na escola. Desse modo, as mediações impregnadas de saberes sociais diferenciados possibilitam a elaboração do pensamento conceitual pelo questionamento e estabelecimento de relações, abstração e generalização. Assim, as interações sociais permitem o desenvolvimento das faculdades mentais (VIGOTSKY, 2000).

\section{CONSIDERAÇÕES FINAIS}

O processo de análise das produções que fazem parte do corpus de estudo pode ser entendido por um ciclo reflexivo, que possibilitou a formação de estruturas de compreensão dos fenômenos investigados, expressos, então, na forma das produções escritas no decorrer deste texto.

A importância atribuída à revisão bibliográfica se deu pela necessidade de compreender uma parcela dos conhecimentos produzidos e validados sobre a educação alimentar e nutricional na infância.

Considerando as categorias que emergiram da análise da pesquisa, concluímos que a família, a escola, os professores, o nutricionista e os meios de comunicação, têm significativa influência para a educação alimentar e nutricional e a formação dos hábitos alimentares na infância. As pesquisas expressam que a conformação dos hábitos alimentares e as características do estilo de vida se iniciam na infância, são consolidadas na adolescência e, muitas vezes, mantidas na idade adulta.

Existem diversos estudos sobre a Educação Alimentar e Nutricional na Infância, mas, na maioria das vezes, não passam de atividades pontuais. Por isso, emerge a necessidade de aprofundamento de pesquisas e ações de educação alimentar e nutricional de modo sistemático e na interação de diferentes sujeitos conforme proposto pelo referencial histórico cultural.

\section{REFERÊNCIAS}

AFONSO, L. G. O professor do 1 ำ ciclo do Ensino Básico como agente fundamental na educação nutricional: análise da sua formação inicial do currículo formal do 1o ciclo. 2008. Monografia. Disponível em: <http://hdl.handle.net/10216/54533>. Origem: Repositório Aberto da Universidade do Porto. Acesso em: 28 nov. 2017.

BENTO, I. C.; ESTEVES, J. M. M.; FRANÇA, T. E. Alimentação saudável e dificuldades para torná-la uma realidade: percepções de pais/responsáveis por pré-escolares de uma creche em Belo Horizonte/MG, Brasil. Revista Ciência \& Saúde Coletiva, Rio de Janeiro, v. 20, n. 8, p. 2.389-2.400, ago. 2015. Disponível em: $<$ http://www.scielo.br/scielo.php?script=sci_arttext\&pid=S1413-81232015000802389\&Ing=en\&nrm=iso>. Acesso em: 5 dez. 2017. 
BERNARDI, L. et al. A interdisciplinaridade como estratégia na prevenção da hipertensão arterial sistêmica em crianças: uma revisão sistemática. Revista Ciência \& Saúde Coletiva, Rio de Janeiro, v. 22, n. 12, p. 3.987-4.000, dez. 2017. Disponível em: <http://www.scielo.br/scielo.php?script=sci_arttext\&pi$\mathrm{d}=\mathrm{S} 1413-81232017021203987 \& \mathrm{lng}=\mathrm{pt} \& \mathrm{nrm}=\mathrm{iso}>$. Acesso em: $16 \mathrm{mar} .2018$.

BONÉ, M. A.; BONITO, J.; CALDEIRA, V. Capacitação de crianças com dificuldades intelectuais para boas práticas alimentares. Revista Holos, 31(3):212-237, 2015. Disponível em: <http://www2.ifrn.edu.br/ojs/ index.php/HOLOS/article/view/2738/1113>. Acesso em: 9 dez. 2017.

BRASIL. A horta escolar dinamizando o currículo da escola. Caderno 1. Projeto TCP/BRA/3003. Brasília: Organização das Nações Unidas para a Agricultura e Alimentação (FAO); Fundo Nacional de Desenvolvimento da Educação (FNDE) do Ministério da Educação (MEC), 2008b. Disponível em: <http://www.educacao. go.gov.br/documentos/nucleomeioambiente/Caderno_horta.pdf>. Acesso em: 28 maio 2017.

. Governo do Estado de São Paulo. Secretaria de Estado da Educação Coordenadoria de Gestão da Educação Básica. Departamento de Desenvolvimento Curricular e de Gestão da Educação Básica. Planejamento escolar. 2012b. Disponível em: <http://deribeiraopreto.edunet.sp.gov.br/plan5.pdf>. Acesso em: 18 jan. 2015.

Ministério da Educação. Base Nacional Comum Curricular. Terceira versão. Brasília: MEC, 2017. Disponível em: <http://basenacionalcomum.mec.gov.br/images/BNCC_publicacao.pdf>. Acesso em: 16 set. 2017.

Ministério da Educação. Secretaria de Educação Básica. Modulo 10: alimentação e nutrição no Brasil I. Coord. Maria de Lourdes Carlos Rodrigues et al. Brasília: Universidade de Brasília, 2007. 93 p.

Ministério da Educação. Secretaria de Educação Básica. Secretaria de Educação Continuada, Alfabetização, Diversidade e Inclusão. Secretaria de Educação Profissional e Tecnológica. Conselho Nacional da Educação. Câmara Nacional de Educação Básica. Diretoria de Currículos e Educação Integral. Diretrizes Curriculares Nacionais Gerais da Educação Básica. Brasília: MEC; SEB; Dicei, 2013.

Ministério da Saúde. Secretaria de Atenção à Saúde. Departamento de Atenção Básica. Política Nacional de Alimentação e Nutrição. Brasília: Ministério da Saúde, 2012c.

Ministério da Saúde. Secretaria de Atenção à Saúde. Departamento de Atenção Básica. Guia alimentar para a população brasileira: promovendo a alimentação saudável. Brasília: Ministério da Saúde, 2008a. 210 p. (Série A. Normas e Manuais Técnicos).

Ministério da Saúde. Secretaria de Atenção à Saúde. Departamento de Atenção Básica. Guia ali-

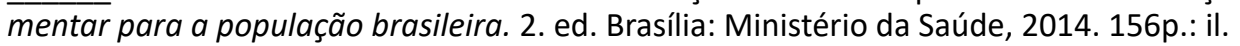

Ministério do Desenvolvimento Social e Combate à Fome. Marco de referência de educação alimentar e nutricional para as políticas públicas. Brasília, DF: MDS; Secretaria Nacional de Segurança Alimentar e Nutricional, 2012a. Disponível em: <http://www.cfn.org.br/wp-content/uploads/2017/03/marco_EAN.pdf>.

Secretaria de Educação Fundamental. Parâmetros Curriculares Nacionais: introdução aos parâmetros curriculares nacionais. Brasília: MEC; SEF, 1997. 126p.

Secretaria de Educação Fundamental. Parâmetros Curriculares Nacionais: Ciências Naturais. Brasília: MEC; SEF, 1998. Disponível em: <http://portal.mec.gov.br/seb/arquivos/pdf/ciencias.pdf>.

CAMBRAIA, R. P. et al. Preferência alimentar de crianças e adolescentes: revelando a ausência de conhecimento sobre a alimentação saudável. Revista Alimentação e Nutrição, Araraquara, 23(3):483-489, 2012. Disponível em: <http://serv-bib.fcfar.unesp.br/seer/index.php/alimentos/article/viewFile/483/1994>. Acesso em: 9 dez. 2017.

CAMPOS, A. A. O. et al. Aconselhamento nutricional de crianças menores de dois anos de idade: potencialidades e obstáculos como desafios estratégicos. Ciência \& Saúde Coletiva, 19(2):529-538, 2014. Disponível em: <http://www.scielo.br/scielo.php?script=sci_arttext\&pi$\mathrm{d}=$ S1413-81232014000200529\&Ing=en\&nrm=iso>. Acesso em: 3 dez. 2017.

COELHO, L. S. V. A. et al. Educational software and improvement of first grade school students' knowledge about prevention of overweight and obesity. Educ Enferm., 34(2):351-359, 2016. Disponível em: <http:// www.scielo.org.co/scielo.php?script=sci_arttext\&pid=S0120-53072016000200015\&Ing=en\&nrm=iso>. Acesso em: 9 dez. 2017.

CORRÊA, A. et al. Diabetes mellitus tipo 1: vivência dos pais em relação à alimentação de seu filho. Alimentação e Nutrição, Araraquara, 23(4):631-637, 2012. Disponível em: <http://serv-bib.fcfar.unesp.br/ seer/index.php/alimentos/article/viewFile/631/1853>. Acesso em: 28 nov. 2017.

CUNHA, E.; SOUSA, A. A.; MACHADO, N. M. V. A alimentação orgânica e as ações educativas na escola: diagnóstico para a educação em saúde e nutrição. Revista Ciência \& Saúde Coletiva, 15(1):39-49, 2010.

DETREGIACHI, C. R. P.; BRAGA, T. M. S. Projeto “Criança Saudável, Educação Dez": resultados com e sem intervenção do nutricionista". Revista de Nutrição, 24(1):51-59, 2011.

GALLEGOS-MARTÍNEZ, J.; REYES-HERNÁNDEZ, J. Representations by Caregivers, Teachers, and Children on Food, Nutrition, Health, and School Breakfast. Revista Invest. Educ. Enferm., 34(2):368-377, 2016. 
JUZWIAK, C. R. Era uma vez... um olhar sobre o uso dos contos de fada como ferramenta de educação alimentar e nutricional. Revista Interface: Comunicação Saúde Educação, 17(45):473-84, 2013.

KLOTZ-SILVA, J.; PRADO, S. D.; SEIXAS, C. M. Comportamento alimentar no campo da alimentação e nutrição: do que estamos falando? Physis Revista de Saúde Coletiva, Rio de Janeiro, 26(4):1.103-1.123, 2016.

LINDSAY, A. C. et al. Child feeding practices and house hold food in security among low-income mothers in Buenos. Revista Ciência \& Saúde Coletiva, v. 17, n. 3, mar. 2012.

LONGO-SILVA, G. et al. Percepções de educadores de creches acerca de práticas cotidianas na alimentação de lactentes: impacto de um treinamento. Revista Ciência \& Saúde Coletiva, 18(2):545-552, 2013.

MADRUGA, S. W. et al. Manutenção dos padrões alimentares da infância à adolescência. Revista Saúde Pública, São Paulo, 46(2):376-386, 2012.

MAIA, E. R. et al. Validação de metodologias ativas de ensino-aprendizagem na promoção da saúde alimentar infantil. Revista de Nutrição, Campinas, 24(1):79-88, 2012.

MARINHO, L. M. F. et al. Situação da alimentação complementar de crianças entre 6 e 24 meses assistidas na Rede de Atenção Básica de Saúde de Macaé, RJ, Brasil. Revista Ciência \& Saúde Coletiva, 21(3):977-986, 2016. MARQUES, E. S. A.; CARVALHO, M. V. C. Prática educativa bem-sucedida na escola: reflexões com base em L. S. Vigotski e Baruch de Espinosa. Revista Brasileira de Educação, v. 22, n. 71, 2017.

MAYER, A. P. F.; WEBER, L. N. D.; TON, C. T. Perfis parentais com base nas práticas educativas e alimentares: análises por agrupamento. Revista Psicologia, Saúde \& Doenças, v. 15, n. 3, dez. 2014.

MORAES, R.; GALIAZZI, M. C. Análise textual discursiva. ljuí: Ed. Unijuí, 2016.

NOBRE, É. B.; BRENTANI, A. V. M.; FERRARO, A. A. Association between maternal lif estyle and preschool nutrition. Revista da Associação Médica Brasileira, v. 62, n. 6, set. 2016.

OLIVEIRA, A. S. et al. Hábitos alimentares de pré-escolares: a influência das mães e da amamentação. Revista de Nutrição, Campinas, 2012.

OLIVEIRA, K. S. Avaliação do material didático do projeto “Criança Saudável - Educação Dez". Interface Comunicação, Saúde, Educação, v. 12, p. 410-10, abr./jun. 2008.

PRADO, S. D. et al. A pesquisa sobre alimentação no Brasil: sustentando a autonomia do campo alimentação e nutrição. Revista Ciência \& Saúde Coletiva, 16(01):107-119, 2011.

RESENDE, V. A.; NAVARRO, A. C. A importância da educação nutricional na infância para prevenção da obesidade. RBONE ? Revista Brasileira de Obesidade, Nutrição e Emagrecimento, São Paulo, 2(8):149-156, 2008.

ROSSI, A.; MOREIRA, E. A. M.; RAUEN, M. S. Determinantes do comportamento alimentar: uma revisão com enfoque na família. Revista de Nutrição, Campinas, 21(6):739-748, 2008.

SCHAURICH, G. F.; DELGADO, S. E. Caracterização do desenvolvimento da alimentação em crianças de 6 a 24 meses. Revista Cefac, 16(5):1.579-1.588, 2014.

SILVA, R. P. N. da et al. Concepções de professores sobre os processos de educação em saúde no contexto escolar. Revista Contexto e Educação, Ijuí: Ed. Unijuí, v. 32, n. 103, p. 146-164, 2017. Disponível em: <http://dx.doi.org/10.21527/2179-1309.2017.103.146-164>. Acesso em: 2 maio 2018.

SILVA, D. A. C. et al. Food marketing targeting children: unveiling the ethical perspectives in the discourse on self-regulation. Revista Ciência \& Saúde Coletiva, Rio de Janeiro, v. 22, n. 7, p. 2.187-2.196, july 2017. Disponível em: <http://www.scielo.br/scielo.php?script=sci_arttext\&pi$\mathrm{d}=\mathrm{S} 1413-81232017002702187 \&$ Ing=en\&nrm=iso>. Acesso em: 16 mar. 2018.

SOLDATELI, B.; VIGO, A.; GIUGLIANI, E. R. J. Adherence to dietary recommendations for preschoolers: clinical trial with teenage mothers. Revista de Saúde Pública, São Paulo, v. 50, 83, 2016. Disponível em: $<$ http://www.scielo.br/scielo.php?script=sci_arttext\&pid=S0034-89102016000100252\&lng=en\&nrm=iso>. Acesso em: 16 mar. 2018.

UEDA, M. H.; PORTO, R. B.; VASCONCELOS, L. A. Publicidade de alimentos e escolhas alimentares de crianças. Revista Psicologia: Teoria e Pesquisa, vol. 30, n. 1, p. 53-61, jan./mar. 2014.

VEGA, J. B.; POBLACION, A. P.; TADDEI, J. A. A. C. Fatores associados ao consumo de bebidas açucaradas entre pré-escolares brasileiros: inquérito nacional de 2006. Ciência \& Saúde Coletiva, 20(8):2.371-2.380, 2015.

VESTENA, R. de F.; SCREMIN, G.; BASTOS, G. D. Alimentação saudável: contribuições de uma sequência didática interativa para o ensino de ciências nos anos iniciais. Revista Contexto e Educação, ljuí: Ed. Unijuí, v. 33, n. 104, p. 365-394, 2018. Disponível em: <http://dx.doi.org/10.21527/2179-1309.2018.104.365394>. Acesso em: 2 maio 2018.

VIGOTSKY, L. S. 1896-1934. A formação social da mente: o desenvolvimento dos processos psicológicos superiores. Organizadores Michel Cole et al. Tradução José Cipolla Neto, Luís Silveira Menna Barreto e Solange Castro Afeche. 7. ed. São Paulo: Martins Fontes, 2007.

. A construção do pensamento e da linguagem. São Paulo: Martins Fontes, 2000.

1896-1934. Pensamento e linguagem. Tradução Jefferson Luiz Camargo. Revisão técnica José Cipolla Neto. 4. ed. São Paulo: Martins Fontes, 2008. 